\title{
Prevalence and determinants of Systemic Hypertension in Inhabitants of high altitude of Nepal
}

\author{
Dipanker Prajapati', Pratima Poudel ${ }^{2}$, Anish Hirachan ${ }^{3}$, Kunjang Sherpa ${ }^{4}$, \\ Bharosa Sharma ${ }^{5}$, Dilasha Karki ${ }^{5}$, Monica Yadav ${ }^{5}$, Santosh Dhakal ${ }^{6}$, Anita Dewan ${ }^{7}$, \\ Rosy Shakya ${ }^{8}$, Binita Tamrakar ${ }^{8}$, Urmila Shakya ${ }^{6}$, Kiran Prasad Acharya ${ }^{4}$ \\ ${ }^{1}$ Cardiologist, ${ }^{4}$ Senior Resident, ${ }^{5}$ Resident Doctor, Department of Cardiology, Shahid Gangalal National Heart Center, \\ Nepal, ${ }^{2}$ Dermatologist, Department of Pediatric Dermatology, Kanti Children's Hospital, Nepal, ${ }^{3}$ Consultant Cardiologist, \\ Department of Cardiology, Nepal Mediciti, Nepal, ${ }^{6}$ Administrative staff, Department of Administration, Shahid \\ Gangalal National Heart Centre, Kathmandu, Nepal, ${ }^{7}$ Matron, Department of Nursing, Shahid Gangalal National Heart \\ Center, Nepal, ${ }^{8}$ Nursing In charge, Department of Nursing, Shahid Gangalal National Heart Center, Nepal, ${ }^{9}$ Consultant \\ Pediatric Cardiologist, Department of Pediatric Cardiology, Shahid Gangalal National Heart Centre, Nepal
}

\section{B S T R A C T}

Background: Several studies have shown increase in prevalence of cardiovascular risk factors in the individuals residing in high altitude in various parts of the world. Aims and Objective: This study was conducted with an aim to estimate the prevalence and determinants of hypertension among the high-altitude population of Jomsom district of Nepal.Materials and Methods: We carried out a prospective camp based survey in Jomsom area on $4^{\text {th }}$ and $5^{\text {th }}$ June of 2017 where we measured the blood pressure, recorded anthropometric measurements like weight, height, BMI, Waist, Hip, Waist/hip ratio and maintained the thorough recorded after verbal consent of the participants. Results: A total of 617 local residents of Jomsom were screened. The mean age was $44.4 \pm 17$. 6 years with predominant female subjects $(53.5 \%$ female vs. $46.5 \%$ male). Hypertension was present in $142(23.0 \%)$ which was significantly lower than in the general population of Nepal as compared to other large scale studies. In addition, alcohol consumption in $29.3 \%$, cigarette smoking in $15.9 \%$ and tobacco consumption in $8.3 \%$ was present. Higher $\mathrm{BMI}$ and waist/hip ratio was significantly associated with male sex and hypertension. Conclusion: The overall prevalence of hypertension is lower among the individuals residing in higher altitude compared to the general population although the other determinants are comparable.

Key words: Hypertension; Cardiovascular risk factors; high altitude population

\section{Access this article online}

Website:

http://nepjol.info/index.php/AJMS DOI: 10.3126/ajms.v11i3.27064

E-ISSN: 2091-0576

P-ISSN: 2467-9100

Copyright (c) 2020 Asian Journal of Medical Sciences

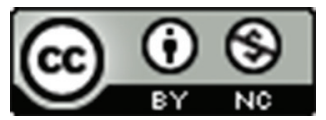

This work is licensed under a Creative Commons Attribution-NonCommercial 4.0 International License.

\section{INTRODUCTION}

A significant proportion of population of Nepal resides at high altitude. There are very few studies done on the prevalence and determinants of systemic hypertension in the people who reside in high altitude of Nepal. Globally about $2 \%$ of the population resides at an altitude of 2500 meters or more. ${ }^{1}$ However, a total of $6.7 \%$ of population of Nepal reside in mountains. ${ }^{2}$ Hypertension is one of the major non communicable diseases with increasing incidence in both developed as well as developing countries and is a common cause of premature mortality and morbidity.
The effect of chronic hypoxia on the systemic blood pressure in the people living in high altitude is uncertain and various studies have shown contradictory results. There is an enhanced vascularization secondary to chronic hypoxia which results in reduction of the total peripheral resistance ultimately maintaining the blood pressure in normal ranges in the people living in mountains. ${ }^{3}$

The objective of this study is to estimate the prevalence and determinants of systemic hypertension in people living in high altitude of Nepal. 


\section{MATERIALS AND METHODS}

A descriptive cross sectional study was carried out in $4^{\text {th }}$ and $5^{\text {th }}$ June of 2017 at Jomsom of Mustang district of Nepal which is situated at an altitude of 2743 meters from sea level. A routine cardiac screening camp of Shahid Gangalal National Heart Center was conducted and a total of 617 adults of more than 18 years of age were screened.

Adults of either sex, who were the permanent resident at the given place, were enrolled in the study. They were explained about the purpose of study and the methods used. Informed verbal consent was taken assuring full confidentiality. The details of the patients which include sex, age, height, weight, BMI, waist and hip circumference were measured and recorded in a predesigned data collection form.

Statistical analysis was performed with statistical software (SPSS-22.0 for windows). Results were analyzed using appropriate statistical methods. P-value was calculated under the predetermined level of significance $(0.05)$ and Confidence interval (CI) of 95\% was constructed. Results were expressed in percentage, mean and standard deviation. Ethical clearance was taken from IRC of Shahid Gangalal National Heart Center, Nepal.

Blood pressure was measured by standard BP cuffs in both arms by auscultatory/manual method and higher of the two readings were taken for analysis. A blood pressure of more than or equal to $140 / 90 \mathrm{mmHg}$ was considered as hypertension as per JNC-7 guidelines.

\section{RESULTS}

There were total 617 people who were screened in the camp, which included $287(46.5 \%)$ male and 330(53.5\%) female. The mean age of the study population was $44.473 \pm 17.6497$ years. Among them, the mean age of male participants was $44.7 \pm 17.8$ years and the mean age of female was $44.3 \pm 17.5$ years.

Hypertension was present in $142(23.0 \%)$ subjects with the mean age of hypertensive patients being $56.8 \pm 14$ years whereas mean age of non-hypertensive subjects was $40.8 \pm 17$ years. There were 80 male with HTN with mean age being $55.7 \pm 15.1$ years and 62 female were diagnosed with HTN with mean age being $58.1 \pm 12.5$ years. Compared to female, male has 1.67 times more likely to have HTN (CI: 1.14 to 2.44 ) which is significant at $95 \%$ CI ( $\mathrm{p}$ value: 0.007 ) as shown in Table 1.

Out of 142 subjects with HTN, 121(85.2\%) were aware of their HTN status but only 81(66.9\%) were using antihypertensive drugs. Among the subjects using antihypertensive drugs, 31(38.2\%) subjects didn't have their Blood Pressure controlled whereas the rest were normotensive. Among the subjects (40, $33.1 \%$ ) who were not using antihypertensive drugs, only $4(10 \%)$ had their Blood pressure controlled. Various anthropometric measurements including height, weight, body mass index (BMI), waist, hip and waist/hip ratio were taken and analyzed as shown in Table 2.

BMI recording revealed that the prevalence of overweight was seen in males, However prevalence obesity was present more in females and was statistically significant (p value: 0.015 ). Also, prevalence of hypertension was directly proportional to increased BMI at 95\%CI ( $\mathrm{p}$ value $<0.001$ ) as shown in Table 3.

Waist/Hip ratio was significantly higher in male at 95\% CI ( $p$ value: 0.007 ) and also significantly higher in hypertensive subjects at $95 \% \mathrm{CI}(\mathrm{p}$ value $<0.001$ ) as shown in Table 4.

\begin{tabular}{|c|c|c|c|c|c|}
\hline & HTN Present & HTN Not Present & Total & OR $(95 \% \mathrm{Cl})$ & p-value \\
\hline \multicolumn{6}{|l|}{ Sex } \\
\hline Male & 80 & 207 & 287 & $1.67(1.14-2.44)$ & 0.007 \\
\hline Female & 62 & 268 & 330 & & \\
\hline Total & 142 & 475 & 617 & & \\
\hline
\end{tabular}

Table 2: Anthropometric measurements

\begin{tabular}{lccc} 
& Minimum & Maximum & Mean \\
\hline Height $(\mathrm{cm})$ & 108 & 180 & 156.399 \\
Weight $(\mathrm{Kg})$ & 32 & 110 & 62.251 \\
BMl $\left(\mathrm{kg} / \mathrm{m}^{2}\right)$ & 14.22222222 & 50.5829904 & 25.45258113 \\
Waist $(\mathrm{cm})$ & 48 & 130 & 86.733 \\
Hip $(\mathrm{cm})$ & 49 & 166 & 92.716 \\
Waist/hip ratio & 0.470588235 & 1.632653061 & 0.935888875 \\
\hline
\end{tabular}




\begin{tabular}{|c|c|c|c|c|c|c|}
\hline & \multicolumn{4}{|c|}{ BMI $\left(\mathrm{kg} / \mathrm{m}^{2}\right)$} & \multirow[t]{2}{*}{ Total } & \multirow[t]{2}{*}{$p$-value } \\
\hline & $\begin{array}{c}\text { Underweight } \\
\quad(<18.5)\end{array}$ & $\begin{array}{c}\text { Normal } \\
(18.5-24.9)\end{array}$ & $\begin{array}{l}\text { Overweight } \\
(25-29.9)\end{array}$ & $\begin{array}{l}\text { Obese } \\
(>30)\end{array}$ & & \\
\hline \multicolumn{7}{|l|}{ Sex } \\
\hline Male & 8 & 70 & 135 & 74 & 287 & 0.015 \\
\hline Female & 9 & 90 & 115 & 116 & 330 & \\
\hline \multicolumn{7}{|l|}{ HTN } \\
\hline Not Present & 13 & 135 & 203 & 124 & 475 & $<0.001$ \\
\hline Present & 4 & 25 & 47 & 66 & 142 & \\
\hline
\end{tabular}

\section{Table 4: Waist/hip ratio measurement}

\begin{tabular}{|c|c|c|c|c|c|}
\hline & Sex & Number & Mean & Std. Deviation & p-value \\
\hline \multirow[t]{3}{*}{ Waist/hip ratio } & Male & 287 & 0.944271948 & 0.061566308 & 0.007 \\
\hline & Female & 330 & 0.928598142 & 0.078498402 & \\
\hline & HTN & Number & Mean & Std. Deviation & p-value \\
\hline Waist/hip ratio & Not Present & 475 & 0.930332427 & 0.076461734 & $<0.001$ \\
\hline
\end{tabular}

\section{DISCUSSION}

Analysis of the results revealed the overall prevalence of hypertension in inhabitants of high altitude of Nepal to be $23 \%$. Our result is in accordance to the study done in Himanchal Pradesh of India by Bhardwaj et al in the year 2010 which revealed the prevalence of $22.5 \% .{ }^{4}$ In contrast to this, results obtained from the study done by Shrestha et al in the year 2012 showed the overall prevalence of hypertension in the population residing in high altitude of Nepal to be $3.7 \%{ }^{5}$ Study performed by Sharma et al in the large scale population of Eastern Nepal in the year 2011 showed the overall prevalence of hypertension in Nepal to be $33.9 \% .{ }^{6}$ This clearly demonstrates the lower prevalence of hypertension in the people living in high altitude than in low altitude. It is probably due to the protective effects of hypobaric hypoxia or chronic hypoxia in the blood pressure which is hypothesized due to the reduction of total peripheral resistance via increased microvasculature.

In our study, a significantly higher prevalence of hypertension was found in males than in females in people of high altitude which accounted for $27.8 \%$ and $18.7 \%$ respectively. Similarly, Male preponderance was seen in another study performed by Raina et al with the prevalence being $12.9 \%$ in males and $6 \%$ in female. ${ }^{7}$ Likewise, the prevalence of hypertension was higher among males living in high altitude as shown in various studies done by Sherpa et al ${ }^{8}$ Negi et al ${ }^{9}$ and Zheng et al. ${ }^{10}$ In contrast to our and above studies a study done in a high altitude region in rural region of Uttarkhand, India revealed higher prevalence of hypertension in females $(34.2 \%)$ than in males $(20.3 \%){ }^{11}$

Obesity is an important indicator of the cardiovascular disease with the emerging trend in our part of the world and has linkage with hypertension and Dyslipidemia. According to our study $30.8 \%$ of the study population had obesity as per the BMI $(>25 \mathrm{~kg} / \mathrm{m} 2)$ with the prevalence of obesity being $25.8 \%$ in males and $35.1 \%$ in females. It was comparable to the study done by Sharma et al where the overall prevalence of obesity in Nepalese population was reported to be $32.5 \%$. Sharma et al also reported the overall prevalence of overweight (BMI $=22-24.9)$ in Nepalese population to be $28.2 \% .{ }^{6}$ However, the overall prevalence of overweight people in our study was $40.5 \%$, with $47.03 \%$ males and 35.15 females being overweight. This clearly signifies burden of overweight and obesity in the people residing in high altitude region of Nepal. The result is in contrary to the study done by Gutierrez et al. ${ }^{12}$ The possible explanation of the increased prevalence of overweight in people residing in high altitude of Nepal could be due to the sedentary life style due to cold weather and increased intake of carbohydrate and dairy products like potatoes, barley, yak milk, ghee, maize, etc. In addition, high intake of homemade alcohol in high altitude region of Nepal can also be an important factor.

Our study showed the overall prevalence of hypertension in obese and overweight population residing in high altitude to be $34.7 \%$ and $18.8 \%$ respectively. This was contrary to the results obtained from the study done by Akintunde et $\mathrm{al}^{13}$ which showed $31.9 \%$ of hypertensive patients were overweight and $25.5 \%$ were obese. This signifies the lower prevalence of hypertension in obese and overweight patient residing in high altitude of Nepal despite the significant proportion of people being overweight or obese.

Abdominal obesity is also of emerging concern in Nepal even in people residing in high altitude. There 
are many previous studies reflecting the high waist hip ratio contributing to hypertension. ${ }^{14}$ Our study showed a significantly higher waist hip ratio in males than in females. In addition, the mean waist hip ratio was higher in hypertensive people than in normotensive individuals with the mean waist hip ratio in hypertensive and normotensive individuals being 0.954 and 0.93 respectively.

The reduced prevalence of hypertension in individuals of high altitude despite the similar prevalence of the risk factors like obesity compared to general population has been shown in many earlier studies. The protective effect of chronic hypoxia,

reduction of blood pressure under hypoxic hypobaric conditions due to the relaxation of smooth muscles, increased microvasculature and collateral circulation and vascularization is one of the hypothesis which still needs to be proved in other large scale studies. ${ }^{15}$ In addition, lower blood pressure in high altitude individuals is also suggested due to increased peripheral capillary density and circulatory nitric oxide levels. ${ }^{16}$

Single centered, small sample with limited time frame and cross sectional study were the major limitations of our study. More prevalence studies especially population based and large scale, multicentered studies are needed to estimate the comprehensive burden of hypertension and its determinants in the high altitude region of Nepal.

\section{CONCLUSION}

The study presented the lower prevalence of hypertension in people residing in the higher altitude of Nepal compared to the general population. This can be correlated with the protective effects of chronic hypoxia and other multiple mechanisms including nitric oxide mediated systemic vasodilatation and reduced total peripheral resistance. The overall burden of hypertension with the prevalence of $23 \%$ is still significant and noteworthy and has to be addressed. However, other determinants of hypertension like overweight, obesity as per the BMI and waist Hip ratio as well as male predominance are almost comparable to the general population.

\section{REFERENCES}

1. Aryal N, Weatherall M, Bhatta YK and Mann S. Blood pressure and hypertension in adults permanently living at high altitude: a systematic review and meta-analysis. High Altitude Medicine \& Biology 2016; 17(3):185-193.

https://doi.org/10.1089/ham.2015.0118
2. Central Bureau of Statistics (2014): Population monograph of Nepal; Vol. 1; Population dynamics; Government of Nepal: National planning commission secretariat.

3. Pocock $G$ and Richards $C D$. Human physiology. Oxford: Oxford University Press, 2013; 497.

4. Bhardwaj R, Kandori A, Marwah R, Vaidya P, Singh B, Dhiman P, et al. Prevalence, awareness and control of hypertension in rural communities of Himachal Pradesh. The Journal of the Association of Physicians of India 2010; 58:423.

5. Shrestha S, Shrestha A and Bhattarai D. Blood pressure in inhabitants of high altitude of Western Nepal. Journal of the Nepal Medical Association 2012; 1(52):188.

https://doi.org/10.31729/jnma.371

6. Sharma SK, Ghimire A, Radhakrishnan J, Thapa L, Shrestha NR, Paudel N, et al. Prevalence of hypertension, obesity, diabetes, and metabolic syndrome in Nepal. International Journal of Hypertension 2011; 19:2011.

https://doi.org/10.4061/2011/821971

7. Raina SK, Chander V, Prasher CL and Raina S. Prevalence of hypertension in a tribal land locked population at high altitude. Scientifica 2016; 2016:3589720.

https://doi.org/10.1155/2016/3589720

8. Sherpa LY, Stigum H, Chongsuvivatwong V, Nafstad $P$ and Bjertness E. Prevalence of metabolic syndrome and common metabolic components in high altitude farmers and herdsmen at $3700 \mathrm{~m}$ in Tibet. High Altitude Medicine \& Biology 2013; 1(14):37-44.

https://doi.org/10.1089/ham.2012.1051

9. Negi PC, Marwaha R, Asotra S, Kandoria A, Ganju N, Sharma R, et al. Prevalence of high altitude pulmonary hypertension among the natives of Spiti Valley - a high altitude region in Himachal Pradesh, India. High Altitude Medicine \& Biology 2014; 15(4):504-510.

https://doi.org/10.1089/ham.2013.1112

10. Zheng X, Yao DK, Zhuo-Ma CR, Tang J, Wang TR, Zhang HH, et al. Prevalence, self-awareness, treatment, and control of hypertension in Lhasa, Tibet. Clinical and Experimental Hypertension 2012; 34(5):328-333.

https://doi.org/10.3109/10641963.2011.649930

11. Kapil U, Khandelwal R, Ramakrishnan L, Khenduja P, Gupta A, Pandey RM, et al. Prevalence of hypertension, diabetes, and associated risk factors among geriatric population living in a high-altitude region of rural Uttarakhand, India. Journal of Family Medicine and Primary care 2018; 7(6):1527.

https://doi.org/10.4103/jfmpc.jfmpc_108_18

12. Díaz-Gutiérrez J, Martínez-González MÁ, Izquierdo JJ, González-Muniesa P, Martínez JA AND Bes-Rastrollo M. Living at higher altitude and incidence of overweight/obesity: prospective analysis of the SUN cohort. PLOS One 2016; 11(11):e0164483.

https://doi.org/10.1371/journal.pone.0164483

13. Akintunde AA, Akinwusi PO, Adebayo RA, Ogunyemi $S$ and Opadijo OG. Burden of obesity in essential hypertension: pattern and prevalence. Nigerian Journal of Clinical Practice 2010; 13(4):399-402.

14. Foulds HJ, Bredin SS and Warburton DE. The relationship between hypertension and obesity across different ethnicities. Journal of Hypertension 2012; 30(2):359-367. https://doi.org/10.1097/HJH.0b013e32834f0b86

15. Ostadal B and Kolar F. Cardiac adaptation to chronic highaltitude hypoxia: beneficial and adverse effects. Respiratory Physiology \& Neurobiology 2007; 158(2-3):224-236. 
16. Narvaez-Guerra O, Herrera-Enriquez K, Medina-Lezama $\mathrm{J}$ and Chirinos JA. Systemic Hypertension at high altitude.
Hypertension 2018; 72(3):567-578.

https://doi.org/10.1161/HYPERTENSIONAHA.118.11140

\section{Authors Contribution:}

DP- Concept and design of the study, manuscript preparation, statistically analyzed and interpreted, Critical revision of the manuscript; PP- Concept and design of the study, critical revision of manuscript and review of the study; AH- Reviewed the literature, helped in preparing first draft of manuscript, collected data;

KS-Collected data, statistically analyzed and interpreted, helped in preparing first draft of manuscript; BS- Reviewed the literature, helped in preparing first draft of manuscript; DK- Collected data and maintained Performa; MY,SD,AD,RS, BT,US- Data Collection; KPA- Collected data, statistically analyzed and interpreted, helped in preparing first draft of manuscript.

\section{Work attributed to:}

Department of Cardiology, Shahid Gangalal National Heart Centre, Kathmandu, Nepal.

Orcid ID:

Dr. Dipanker Prajapati - (D https://orcid.org/0000-0003-3704-0324

Dr. Krishna Prasad Acharya - (iD https://orcid.org/0000-0003-2765-4242

Dr. Kunjang Sherpa - (1) https://orcid.org/0000-0003-1136-6983 